\title{
A novel segmental absence of intestinal musculature with small intestinal stenosis: a case report
}

\author{
Kosuke Kashiwagi ${ }^{1}$, Keisuke Jimbo ${ }^{1 *}$ D, Kenji Hosoi ${ }^{1}$, Go Miyano ${ }^{2}$, Takahiro Kudo ${ }^{1}$, Atsuyuki Yamataka ${ }^{2}$ and \\ Toshiaki Shimizu'
}

\begin{abstract}
Background: Segmental absence of intestinal musculature (SAIM) is a rare cause of intestinal obstruction and perforation due to partial or complete defects in the intestinal muscularis propria in neonates and is occasionally observed in adulthood.

Case presentation: The first case of small intestinal stenosis derived from SAIM, which was difficult to differentiate from Crohn's disease (CD), is reported. A 4-year-old girl presented with abdominal pain, anemia, and a positive fecal occult blood test. She was initially diagnosed with CD and started on treatment. Because her gastrointestinal symptoms persisted, her previous pediatricians tried to carry out capsule endoscopy, but it was not possible because the patency capsule was retained. Therefore, she was referred to our institute and re-evaluated. The patency capsule examination was repeated to re-evaluate small intestinal passage, but it stagnated again. Abdominal ultrasonography showed a poorly deformable intestinal tract that narrowed rapidly from the dilated segment and had a thin wall with an irregular laminar structure. In addition, unlike the typical ultrasonic CD findings, the power Doppler signal enhancement at the intestinal wall and "creeping fat sign" were not found. The patient was referred for laparoscopic observation to pediatric surgeons, who confirmed a prominently dilated intestinal tract $40 \mathrm{~cm}$ proximal to the ileocecal valve, which was resected. Histopathological findings showed longitudinal muscle hypoplasia of the resected, dilated intestinal tract and fat replacement of the muscle layer. At the stenosis site, the muscle layer was fibrotic and showed incomplete muscle arrangement. Because of these findings, she was diagnosed with SAIM. After the surgical treatment, no gastrointestinal symptoms relapsed, and the fecal occult blood test has remained negative for 2 years. Moreover, 8 months after surgery, double-balloon endoscopy showed no abnormalities, such as a longitudinal ulcer and cobblestone appearance.
\end{abstract}

Conclusions: In the present case, SAIM involved not only intestinal ileus and perforation, but also small intestinal stenosis. Although no other reports have demonstrated the usefulness of abdominal ultrasonography for the diagnosis of SAIM, the present report suggests that ultrasonography may be useful for differentiating SAIM from CD by close observation of the area around the small intestinal stenosis.

Keywords: Crohn's disease, Creeping fat sign, Power Doppler, Ultrasonography

\footnotetext{
* Correspondence: kjinbo@juntendo.ac.jp

'Department of Pediatrics, Juntendo University Faculty of Medicine, 2-1-1

Hongo, Bunkyo-ku, Tokyo 113-8421, Japan

Full list of author information is available at the end of the article
}

C C The Author(s). 2020 Open Access This article is licensed under a Creative Commons Attribution 4.0 International License, which permits use, sharing, adaptation, distribution and reproduction in any medium or format, as long as you give appropriate credit to the original author(s) and the source, provide a link to the Creative Commons licence, and indicate if changes were made. The images or other third party material in this article are included in the article's Creative Commons licence, unless indicated otherwise in a credit line to the material. If material is not included in the article's Creative Commons licence and your intended use is not permitted by statutory regulation or exceeds the permitted use, you will need to obtain permission directly from the copyright holder. To view a copy of this licence, visit http://creativecommons.org/licenses/by/4.0/ The Creative Commons Public Domain Dedication waiver (http://creativecommons.org/publicdomain/zero/1.0/) applies to the data made available in this article, unless otherwise stated in a credit line to the data. 


\section{Background}

Segmental absence of intestinal musculature (SAIM) is a rare disease associated with intestinal obstruction and perforation in all ages due to partial or complete defects in the intestinal muscularis propria [1]. In 1967, SAIM was initially reported as a cause of intestinal obstruction in neonates $[2,3]$. It was known as a phenomenon of spontaneous focal perforations of the intestinal tract or ileus without clinical and histological features of necrotizing enterocolitis [4]. SAIM was often diagnosed after intestinal obstruction and perforation in newborns, but some cases were diagnosed in adulthood with minor symptoms in childhood [3, 5-7]. The intestine without its muscularis propria developed intestinal wall thinning and hypoperistalsis [8], and most of the muscle defect portion of the intestine had no Auerbach and Meissner plexuses [9]. To the best of our knowledge, cases of small intestinal stenosis derived from SAIM have not been reported. A case of a child with small intestinal stenosis due to SAIM, in which ultrasonography played an important role in differentiating SAIM from Crohn's disease (CD), is reported.

\section{Case presentation}

A 4-year-old girl with a past history of Kawasaki's disease at 1 year of age developed abdominal pain and anemia (hemoglobin: $4.8 \mathrm{~g} / \mathrm{dL}$ ) with a positive fecal occult blood test. Her family had no apparent medical history. She was therefore referred to a local hospital by her doctor. Abdominal contrast computed tomography on admission showed focal small intestinal wall thickening and dilatation, and several un-cascaded small ulcers were detected by colonoscopy at the terminal ileum, and she was diagnosed as having $\mathrm{CD}$. She was started on 5-aminosalicylic acid (5-ASA) and partial enteral nutrition which means the patient receives $50 \%$ of her calories from the elemental diet, and the remainder from the low-fat diet, but her abdominal pain persisted. For further evaluation of the small intestine, upper gastrointestinal and small bowel series

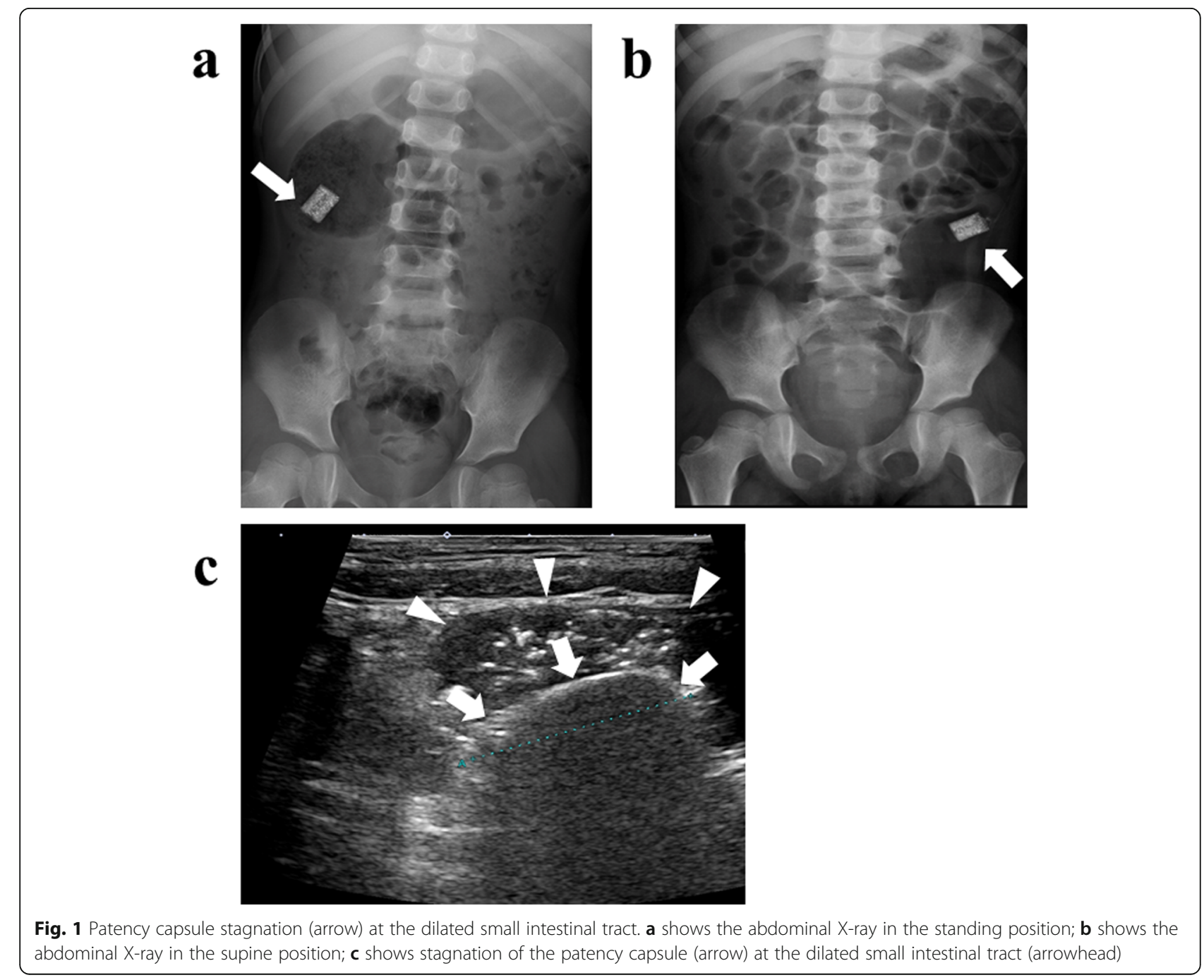


was performed using X-ray contrast media was performed, but no obvious abnormalities could be confirmed. Therefore, previous pediatricians attempted carry out capsule endoscopy, but its feasibility was uncertain due to retention of the patency capsule (PC). In addition, adult gastroenterologists were consulted in an attempt to perform small intestinal double-balloon endoscopy, but due to technical difficulties the intestinal lesion could not be targeted.

Therefore, in 6 years old, the patient was referred to our institute for re-evaluation of her illness. Anthropometric measurements included height and weight were $111.4 \mathrm{~cm}$ (- 0.4 standard deviation) and $18.1 \mathrm{~kg}$ (- 0.6 standard deviation), respectively, suggesting no growth failure was apparent. On physical examination, no remarkable abnormalities were found. Laboratory examinations at that outpatient visit showed the hemoglobin level improving from $4.8 \mathrm{~g} / \mathrm{dL}$ to $12.1 \mathrm{~g} / \mathrm{dL}$, C-reactive protein level of $0.05 \mathrm{mg} / \mathrm{dL}$, and fecal occult blood of $189 \mathrm{ng} / \mathrm{mL}$ (normal range, $0-80 \mathrm{ng} / \mathrm{mL}$ ). A positive fecal occult blood finding indicated re-evaluation with ileoscopy and total colonoscopy with biopsy, but there were no abnormal findings. Patency capsule was re-performed, to re-evaluate the obstruction of small bowel transit, but it retained again. At that time, abdominal X-ray and ultrasonography showed dilatation of the small intestine with the PC's stagnation. (Fig. 1). Abdominal ultrasonography demonstrated a poorly deformable intestinal tract, which narrowed rapidly from the dilated segment and had a thin wall with an irregular laminar structure. In addition, unlike the typical ultrasonic CD findings, power Doppler signal enhancement at the intestinal wall and the "creeping fat sign" [10] in the surrounding area of the intestinal wall were not found (Fig. 2). Although SLCO2A1 sequencing was performed to differentiate this from chronic enteropathy associated with $S L C O 2 A 1$, in which small intestinal stenosis forms with the healing of multiple ulcers [11], no mutations could be detected. The patient was referred to pediatric surgeons for laparoscopic observation, and they confirmed a prominently dilated intestinal tract $(47 \times 47 \times$ $30 \mathrm{~mm}) 40 \mathrm{~cm}$ proximal to the ileocecal valve, which was resected. Macroscopically, the resected intestinal tract had a thin wall and stenosis of $7 \mathrm{~mm}$ in diameter, with thickening of the surrounding intestinal wall at the proximal portion. (Fig. 3). Histopathological findings showed longitudinal muscle hypoplasia of the resected dilated intestinal tract and fat replacement of the muscle layer. At the stenosis site, the muscle layer was fibrotic and showed incomplete muscle arrangement (Fig. 4). Because of these findings, she was diagnosed with SAIM. After the surgical treatment, the patient presented with no adverse event from surgery and no gastrointestinal symptoms relapsed. Fecal occult blood test remained negative without the use of 5-ASA and partial enteral nutrition for 2 years. Moreover, 8 months after surgery, double-balloon endoscopy showed no abnormalities, such as a longitudinal ulcer and cobblestone appearance.

\section{Discussion and conclusions}

Although the cause of the small intestinal intrinsic muscle layer loss in SAIM remains unknown, congenital or acquired factors have been considered. Most cases of congenital SAIM were reported in preterm and lowbirthweight infants, and some researchers hypothesised that SAIM was caused by dysplasia of the small intestinal muscle layer in the embryonic period or as a result of transient ischemia after birth $[5,6,8,9]$. In particular,
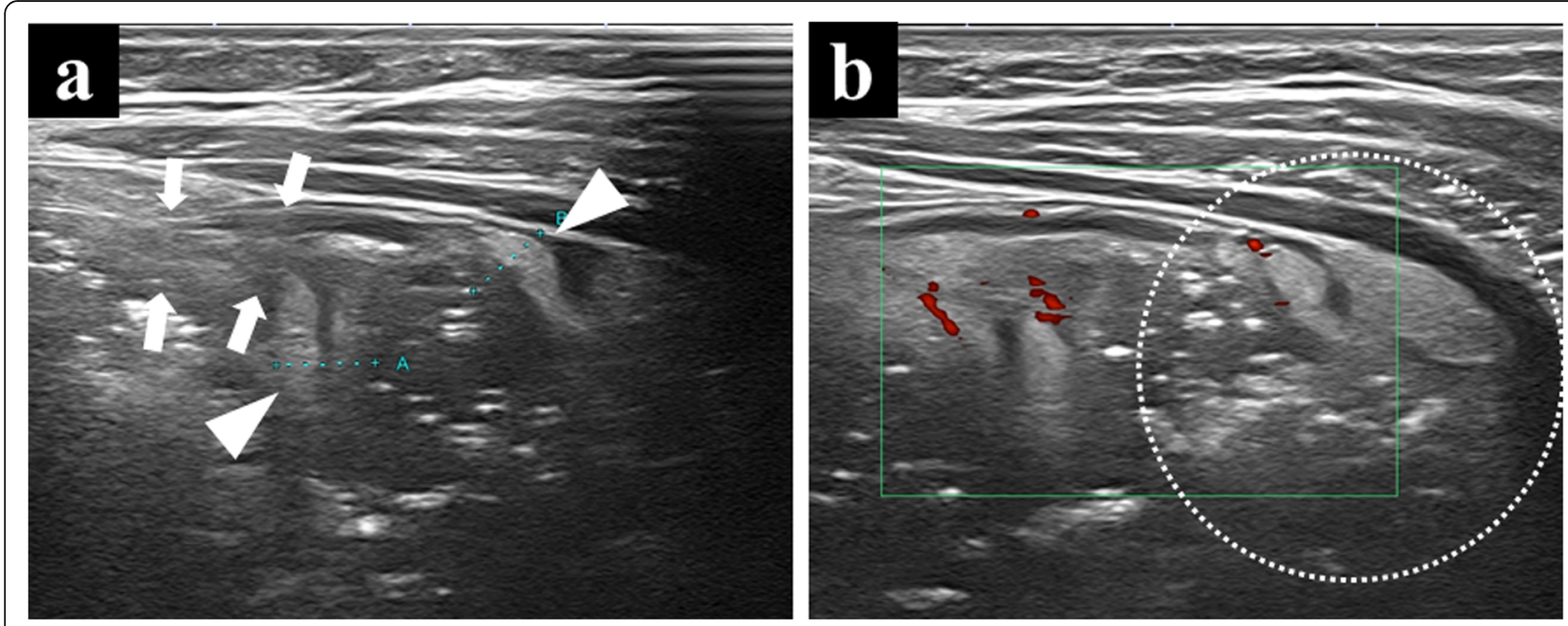

Fig. 2 Abdominal ultrasonic findings of the intestinal lesion with a high-frequency 11-MHz linear transducer. a shows the poorly deformable intestinal tract, which narrows rapidly (arrow) from the dilated segment (arrowhead) and has a thin wall with irregular laminar structure; $\mathbf{b}$ shows the peripheral side of the focally narrowed intestinal tract that has no power Doppler signal enhancement and no "creeping fat sign" around the lesion 


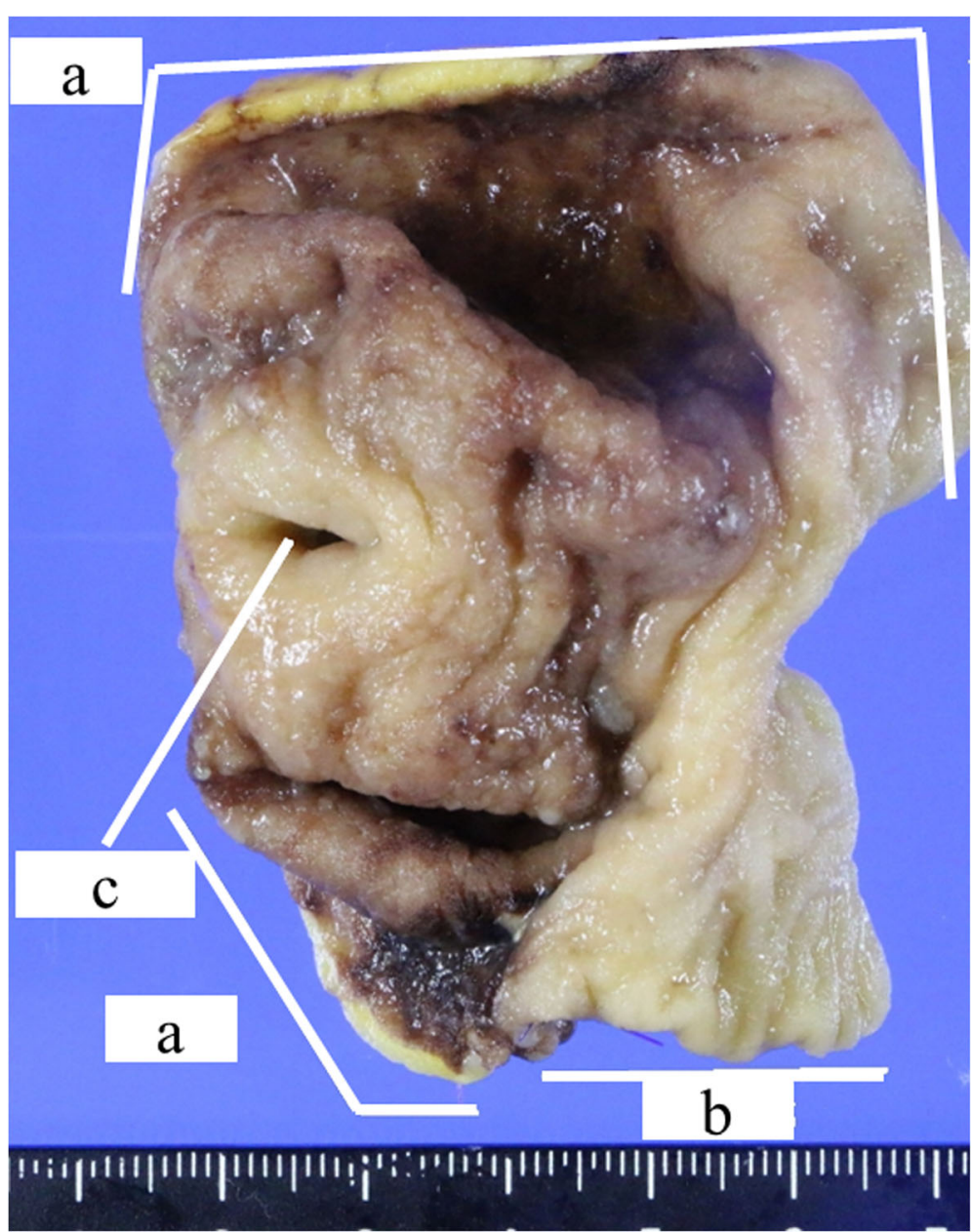

Fig. 3 Macroscopic findings of the resected intestinal tract. a shows the dilated portion with the thin intestinal wall; $\mathbf{b}$ shows normal small intestine; $\mathbf{c}$ shows the peripheral side of the intestinal stenosis of $7 \mathrm{~mm}$ in diameter with thickening of the surrounding wall through which the patency capsule $(26 \mathrm{~mm} \times 11 \mathrm{~mm})$ cannot pass

typical congenital SAIM presented clinically as intestinal perforation or obstruction in neonates and early childhood. In contrast, acquired SAIM cases in adulthood were reported to have intestinal ischemia secondary to hypertension or chronic constipation involved in the onset of acquired SAIM [12, 13]. Our present patient presented with no past history of hypertension and chronic constipation, hence a diagnosis of congenital SAIM was confirmed.

According to adult and pediatric case reports and systematic reviews from 1997 to 2016 identified in a PubMed search for segmental absence of intestinal musculature, 2, 16 , and 8 cases occurred in the duodenum, small intestine ( 7 cases: jejunum, 9 cases: ileum), and colon ( 6 cases: sigmoid colon, 1 case: ascending colon, 1 case: descending colon), respectively. These SAIM cases were generally diagnosed after emergency surgery due to intestinal perforation $[6,7,12-18]$. Although the present case involved the ileum, which was a relatively typical site in previous reports, cases with small intestinal stenosis that were diagnosed before intestinal perforation have not been previously reported. In addition, there have been no published papers reporting ultrasonic imaging findings of SAIM, including cases in which ultrasonography contributed to the diagnosis, as in the present case.

Although SAIM is characterized by thinning of the intestinal tract due to histological hypoplasia or loss of the inner muscular layer, but maintenance of the mucosal layer, a case in which the muscle defect portion of the intestinal wall was replaced by fibrous tissue has been reported [7]. The histopathology of the present case also showed the same findings as previously reported, and thus some recurrent inflammatory damage in the dilated intestinal tract may have resulted in scarring and fibrosis during repeated mucosal healing of the ulcerous lesion and small bowel stenosis. Furthermore, in the present case, there appeared to be intestinal congestion in dilated intestine, which caused ulcerative bleeding and anemia. 


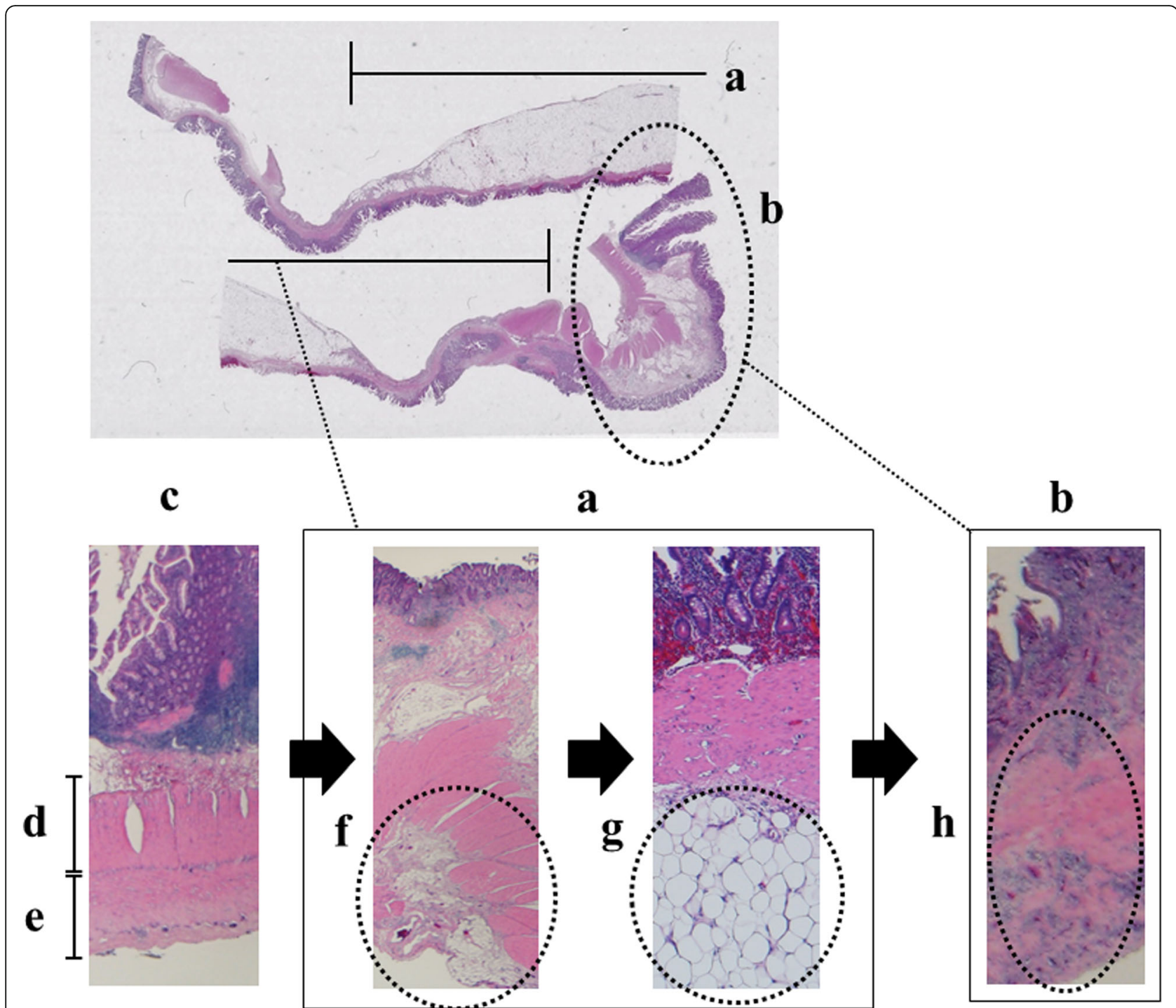

Fig. 4 Histopathological findings of the resected intestinal tract. a shows the segment of intestinal dilation; $\mathbf{b}$ shows the segment of intestinal stenosis; c shows a normal intestinal portion; $\mathbf{d}$ shows the normal circular muscle layer; $\mathbf{e}$ shows the normal longitudinal muscle; $\mathbf{f}$ shows hypoplastic longitudinal muscle in the dilated portion; $\mathbf{g}$ shows adipose tissue replacing hypoplastic muscle in the dilated portion; $\mathbf{h}$ shows the incomplete muscle layer with fibrosis in the intestinal stenosis

On ultrasonic examination, it was reported that ultrasonic Doppler signal enhancement of the thickened intestinal wall [19] and hyperechoic thickening of extraintestinal stromal tissue, called the "creeping fat sign" [10], were considered to be essential findings for making a diagnosis of $\mathrm{CD}$. In contrast, no power Doppler signal of the thickened intestinal wall with high echogenicity might suggest intestinal stenosis. The present case had intestinal stenosis similar to the ultrasonic findings of $\mathrm{CD}$, but neither Doppler signal enhancement nor the "creeping fat sign" around it. Therefore, to differentiate SAIM and CD by ultrasonography, it might be useful to identify atypical $C D$ findings around the stenotic lesion, but further work is needed in larger cohorts. In addition, in some SAIM cases, it was reported that they had other lesions of SAIM within the intestinal tract [1], but double-balloon endoscopy confirmed no other SAIM lesions in the present case.

In conclusion, a novel SAIM case with small intestinal stenosis that was difficult to differentiate from typical CD was reported. The SAIM involved not only intestinal ileus and perforation, but also small intestinal stenosis. Although no other reports have demonstrated the usefulness of abdominal ultrasonography for the diagnosis of SAIM, this report suggests that ultrasonography may be useful for differentiating SAIM from $C D$ by close observation of the area around the small intestinal stenosis. 


\section{Abbreviations}

CD: Crohn's disease; 5-ASA: 5-aminosalicylic acid; PC: Patency capsule; SAIM: Segmental absence of intestinal musculature

\section{Acknowledgements}

The authors would like to express their appreciation to the patient and her parents.

\section{Authors' contributions}

All authors were associated with the care of this patient. KK, HK, and JK wrote the initial draft of the manuscript. JK, GM, KT, YA, and ST critically approved and revised the overall content of the manuscript. All authors read and approved the final manuscript.

\section{Funding}

The authors had no funding sources for this study.

\section{Availability of data and materials}

All data generated or analyzed during this study are included in this published article.

\section{Ethics approval and consent to participate}

Not applicable.

\section{Consent for publication}

Written, informed consent was obtained from the parents of the patient for publication of this case report and any accompanying images.

\section{Competing interests}

The authors declare that they have no competing interests.

\section{Author details}

'Department of Pediatrics, Juntendo University Faculty of Medicine, 2-1-1 Hongo, Bunkyo-ku, Tokyo 113-8421, Japan. ${ }^{2}$ Department of Pediatric General and Urobenital Surgery, Juntendo University Faculty of Medicine, 2-1-1 Hongo, Bunkyo-ku, Tokyo 113-8421, Japan.

Received: 24 March 2020 Accepted: 10 August 2020

Published online: 17 August 2020

\section{References}

1. Rewhorn M, Oliphant R, Jackson A, Keltie R, Going J, Finn P. Perforation of the sigmoid colon secondary to segmental absence of the intestinal musculature (SAIM) in an adult. Int J Color Dis. 2015;30:143-4.

2. Emanuel B, Gault J, Sanson J. Neonatal intestinal obstruction due to absence of intestinal musculature: a new entity. J Pediatr Surg. 1967;2:332-5.

3. Izraeli S, Freud E, Mor C, Litwin A, Zer M, Merlob P. Neonatal intestinal perforation due to congenital defects in the intestinal muscularis. Eur J Pediatr. 1992;151:300-3.

4. Tamai M, Satoh M, Tsujimoto A. Segmental muscular defects of the intestine: a possible cause of spontaneous perforation of the bowel in adults. Hum Pathol. 2013:44:2643-50.

5. Huang SF, Vacanti J, Kozakewich H. Segmental defect of the intestinal musculature of a newborn: evidence of acquired pathogenesis. J Pediatr Surg. 1996;31:721-5.

6. Nawar NA, Sawyer PR. Segmental absence of intestinal musculature in a 64year-old female: case report and literature review. Am J Case Rep. 2016;17: 749-54

7. Oretti C, Bussani R, Janes A, Demarini S. Multiple segmental absence of intestinal musculature presenting as spontaneous isolated perforation in an extremely low-birth-weight infant. J Pediatr Surg. 2010;45:E25-7.

8. Carroll RL Jr. Absence of musculature of the distal ileum: a cause of neonatal intestinal obstruction. J Pediatr Surg. 1973;8:29-31.

9. De Villiers DR. Ischaemia of the colon: an experimental study. Br J Surg. 1966:53:497-503.

10. Golder WA. The "creeping fat sign" - really diagnostic for Crohn's disease? Int J Color Dis. 2009;24(1):1-4

11. Umeno J, Esaki M, Hirano A, Fuyuno Y, Ohmiya N, Yasukawa S, et al. Clinical features of chronic enteropathy associated with SLCO2A1 gene: a new entity clinically distinct from Crohn's disease. J Gastroenterol. 2018;53:907-15.
12. Aldalati $\mathrm{O}$, Phelan $\mathrm{C}$, Ibrahim $\mathrm{H}$. Segmental absence of intestinal musculature (SAIM): a case report in an adult. BMJ Case Rep. 2009. https://doi.org/10.1136/bcr.01.2009.1425.

13. Nandedkar SS, Malukani K, Patidar E, Nayak R. Segmental absence of intestinal musculature: a rare case report. Int J Appl Basic Med Res. 2015;5:222-4.

14. Davis JS, Ryan ML, Shields JM, Sola JE, Perez EA, Neville HL, et al. Segmental absence of intestinal musculature: an increasingly reported pathology. J Pediatr Surg. 2012:47:1566-71.

15. Morikawa N, Namba S, Fujii Y, Sato Y, Fukuba K. Intrauterine volvulus without malrotation associated with segmental absence of small intestinal musculature. J Pediatr Surg. 1999;34:1549-51.

16. Jain S, Wadhwa N, Munjal S. Segmental absence of intestinal musculature with intestinal atresia and ileal perforation. Pathology. 2009;41:596-8.

17. Dzieniecka M, Grzelak-Krzymianowska A, Kulig A. Segmental congenital defect of the intestinal musculature. Pol J Pathol. 2010;61:94-6.

18. Athanazio DA, Rocha MT, Mattos AP, Ribeiro TC, Sorte NC, Freitas LA, et al. Segmental absence of intestinal musculature - presentation in a 10-year-old boy with an extensive involved segment. Fetal Pediatr Pathol. 2015;34:128-32.

19. Allocca M, Fiorino G, Bonifacio C, Furfaro F, Gilardi D, Argollo M, et al. Comparative accuracy of bowel ultrasound versus magnetic resonance enterography in combination with colonoscopy in assessing Crohn's disease and quiding clinical decision-making. J Crohns Colitis. 2018;12:1280-7.

\section{Publisher's Note}

Springer Nature remains neutral with regard to jurisdictional claims in published maps and institutional affiliations.
Ready to submit your research? Choose BMC and benefit from:

- fast, convenient online submission

- thorough peer review by experienced researchers in your field

- rapid publication on acceptance

- support for research data, including large and complex data types

- gold Open Access which fosters wider collaboration and increased citations

- maximum visibility for your research: over $100 \mathrm{M}$ website views per year

At $\mathrm{BMC}$, research is always in progress.

Learn more biomedcentral.com/submissions 